\title{
Perceptions of Augmented Reality (AR): A Motivational Approach to the Technology Acceptance Model (TAM) for Pre-service Teachers
}

\author{
Lamees Abdulrahman Alaulamie*, Abeer Aidh Alshwiah \\ Faculty of Educational Technology, Imam Abdulrahman Bin Faisal University, Saudi Arabia
}

Received June 14, 2021; Revised August 3, 2021; Accepted August 22, 2021

\section{Cite This Paper in the following Citation Styles}

(a): [1] Lamees Abdulrahman Alaulamie, Abeer Aidh Alshwiah, "Perceptions of Augmented Reality (AR): A Motivational Approach to the Technology Acceptance Model (TAM) for Pre-service Teachers," Universal Journal of Educational Research, Vol. 9, No. 9, pp. 1664 - 1675, 2021. DOI: 10.13189/ujer.2021.090907.

(b): Lamees Abdulrahman Alaulamie, Abeer Aidh Alshwiah (2021). Perceptions of Augmented Reality (AR): A Motivational Approach to the Technology Acceptance Model (TAM) for Pre-service Teachers. Universal Journal of Educational Research, 9(9), 1664 - 1675. DOI: 10.13189/ujer.2021.090907.

Copyright $\odot 2021$ by authors, all rights reserved. Authors agree that this article remains permanently open access under the terms of the Creative Commons Attribution License 4.0 International License

\begin{abstract}
The main purpose of this study was to investigate pre-service teachers' perceptions of augmented reality (AR) technology and their intention to use it in their future careers. This involved integrating the Technology Acceptance Model (TAM) with part of the Instructional Materials Motivation Survey (IMMS) to examine the learners' perceived ease of use (PEU) and perceived usefulness (PU) of AR, and how this affected their attention (ATT) in learning, and intention to use (ITU) AR in their future careers. An AR application was applied to affix virtual objects to learners' real world over seven weeks of an Educational Technology course. An online quantitative questionnaire was developed and administered to 101 students in a purposive sample. A descriptive correlational research design was adopted in this study. The results indicate that the students' PU for AR and their ATT while using it were significant predictors of their ITU for this technology in future, while PEU was not a significant predictor of ITU. However, the students' PU and PEU were significant predictors of their perception of AR's capacity to sustain their attention (ATT) while learning. The intention of this study was to pave the way to expand TAM by highlighting an intrinsic motivation variable.
\end{abstract}

Keywords Augmented Reality, Higher Education, Technology Acceptance Model, Instructional Materials Motivation Survey, Attention

\section{Introduction}

These days, there is a widespread tendency for many teachers to try and move away from using traditional teaching methods. In some places, such methods have produced satisfactory results. This reflects an attempt to allow learners to construct their own knowledge, rather than merely acquiring it, with a view to enhancing and enriching their learning experience, making it more interesting $[24,26,36]$. This shift towards constructivism can be brought about by adopting Web 0.2 collaboration tools, three dimensional (3D) virtual worlds and augmented reality (AR), which is the focus of this study [26].

In 1968, US Internet pioneer, Ivan E. Sutherland introduced augmented reality (AR) technology, using devices mounted on headsets (cited in [22]), like the more recent Snapchat Glasses and Google Glasses. In the current contemporary setting, AR has been used on mobile phones and combined with quick response $(\mathrm{QR})$ codes (for example, the IKEA Catalogue) [22, 40]. This interactive technology produces $3 \mathrm{D}$ virtual objects that overlay the real world $[3,5,41]$.

AR has become one of the main focuses of education research over recent years [3], as it can introduce text, 
images, audio- and video content, and even 3D models, superimposed on a real-time scene $[41,54]$. This feature adds life and interactivity to a learning scenario. Thus, teachers have been encouraged to use AR, as it can support a range of pedagogies, such as:

- Constructivist learning, since it enables students to make deep connections in their knowledge by engaging with peers, tasks and resources [31].

- Situated learning by bringing an authentic environment [17] and 'situated scaffolding' to the classroom [8].

- Games-based learning by creating digital role-play games to make the learning more relevant to real life [9].

- Enquiry-based learning by providing information that is contextually applicable to the topic being presented [27].

This study was conducted in a College of Education that prepares pre-teachers for their future careers. One of the College's goals is to ensure that students use technology that engages them and motivates them to learn. The most effective way of achieving this is to enable trainee teachers to practice the skills required for their future professional life. On the College's Instructional Technology course, some state-of-the-art technologies are presented to the trainees, with most of the course topics covering the basics of technology and instructional design. However, it is rare for pre-teachers to be given a chance to discover and implement these recent technologies for themselves. Therefore, this current study aimed to present AR to students, so that they could understand it and become aware of how it might be used. In addition, this study aimed to increase students' motivation while using technology, encouraging them to access diverse media in the process of constructing their knowledge. The rationale for this approach was based on the researchers' observations that the students had low motivation to engage in purely discussion-based activities. The researchers therefore planned to investigate students' perceptions of AR use (perceived usefulness [PU], perceived ease of use [PEU]) in an attempt to establish whether it affected their attention (ATT) and intention to use it in future (ITU).

\subsection{Purpose of the Study}

It is important to investigate learners' actual experiences of using $\mathrm{AR}$, as it will assist educators in its successful implementation [11]. Moreover, it is essential to ascertain learners' willingness to use AR, as their behavioural intention to investigate the learning topic in greater depth may relate to their ITU for AR in future. Thus, the main purpose of this paper is to identify the factors affecting pre-teachers' perceptions of AR (namely, PU and PEU), which could predict their ATT while learning and increase their ITU for AR in future.
The intrinsic motivation factor is one of the most important variables investigated by researchers in the context of technology acceptance. In the literature, the original TAM concentrated more on extrinsic motivation than on the factors of intrinsic motivation, revealing a need to explore these in depth. The present researchers therefore consider ATT to be a construct of intrinsic motivation that could be added to the TAM to help expand it. The originality of this study lies in its exploration of the PU, PEU and ITU of AR by examining learners' ATT that is introduced into the TAM. The present study subsequently examines the impact of AR on pre-service teachers' ITU for this technology in their future careers.

\section{Literature Review}

\subsection{Augmented reality (AR)}

The field of AR has received considerable critical attention in recent literature, particularly in terms of its impact on education [8, 51, 54]. AR can help students develop critical thinking and gain deeper understanding, as it presents abstract concepts in the form of 3D shapes and objects across diverse learning contexts [50]. It supports the theory of 'learning by doing', as its interactive features can introduce new learning experiences into the classroom [26]. Moreover, it can help students develop problem-solving and communication skills, as well as enhancing their creative thinking, as it is motivating which contributes to students' learning outcomes [8, 19]. In brief, it introduces more interactive instruction, authentic contexts, and a friendly interface, while enriching visualisation in the classroom [17, 54].

To shed more light on the effect of AR on learners' achievement, Wang and Chi [55] created an AR application to develop learners' comprehension of the earth revolving around the sun. They found that AR improved the learners' achievement and satisfaction with their course, while reducing their anxiety. In the same vein, Martins et al. [37] found that AR could be used as a musical educational tool that impacts teaching and learning amongst children. The reason is that AR is a tool that is easy for non-specialist students and teachers to use. The above researchers noted that most of the sampled children interacted with the application. They found it usable, and they liked it.

Conversely, pre-service teachers have been unsure about using AR in education, as Rahmat and Nizar [42] found. This was justified as the pre-service teachers being prone to regard technology as a tool for socializing or entertainment, rather than for education, due to the limited availability of teaching and learning apps. In contrast, Martins et al. [37] classified the challenges that can hinder the effective use of AR, namely, (1) physical and technological issues surrounding the need for advanced 
technological knowledge and support, (2) sociocultural issues related to the provision of safe and healthy technology use for students and teachers in the classroom - while avoiding an over-dependence on technology, as this can hinder learning, and (3) pedagogical and management issues, including the need for teachers to be trained in the use of AR, so they can feel secure and confident about using this technology in the classroom [17, 37]. Similarly, Chiang, Yang and Hwang [12] claim that AR distracts students.

\subsection{The Motivation Model and Theory}

The ARCS Model, referring to the four components of Attention, Relevance, Confidence and Satisfaction, was developed by Keller [28] to target individuals' understanding and motivation for learning. It represents an instructional design model and motivation theory with a systematic process, beginning by identifying the issues, proceeding to the design and development of procedures, and ending by evaluating the results [29]. This Model is adopted as a means of increasing students' motivation for learning [33]. Students' motivation is therefore identified as a critical factor in the success of a learning process [59].

Thus, the ARCS Model may be used to try and understand an individual's motivation in the domain of computer-based learning [33]. Motivation can help maintain students' satisfaction at an optimal level in difficult learning environments, such as online courses [7]. Based on a review of the relevant literature conducted by Li and Keller [33], most existing studies have adopted the four components of the ARCS Model, but some have concentrated on single components, or two components combined, such as Relevance and Confidence together.

In the AR scholarship, the ARCS Model was followed by the Instructional Materials Motivation Survey (IMMS), which was designed according to the theoretical framework of motivation concepts that were originally presented in the ARCS Model [30]. According to Keller [30], this survey "was designed to measure reactions to self-directed instructional materials" and it is a suitable tool for computer-based learning environments and online courses (p.277). The original version of the IMMS includes 36 items, consisting of four main constructs: attention, relevance, confidence, and satisfaction [30].

The ARCS Model has been used in the literature to try and understand the motivational aspects of AR (for example, [11, 18]). In particular, Di Serio et al. [18] conducted a case study to investigate the impact of AR on students' motivation on a visual art course, using the IMMS questionnaire. The above study consisted of two teaching scenarios for the same 55 students, with the questionnaire distributed after each scenario. The first scenario involved teaching the students with just one slide, while the second consisted of instruction using AR.
Moreover, the researchers sought to identify whether there was any variation between scenarios across the four components of the IMMS. In this regard, the results revealed that there is a significant difference in students' motivation, attention and satisfaction between the two scenarios attributed to AR.

To explore the impact of AR on learners' motivation in greater depth, Cheng [11] used the IMMS questionnaire to investigate the relationship between motivation, cognitive load, and attitude, where an AR book was used. The IMMS was administered to measure the students' motivation, focusing on the components of attention, confidence, and satisfaction. It also endeavoured to ascertain whether the students' perceptions of cognitive load and motivation played a role in shaping their attitudes. Significant positive relationships were found between the students' intention, attention, confidence and satisfaction. Moreover, there were significant positive relationships between the PU and the students' attention, confidence and satisfaction. Indeed, attention and confidence emerged as variables that mediated between PU and the students' ITU for AR.

Gaining and sustaining an individual's attention is one of the constructs of the ARCS Model [28]. In the learning process, it is important to gain students' attention in the first instance, but it is even more valuable to sustain their attention, since it is a prerequisite for learning [28]. Keller [30] defines attention as "capturing the interest of learners; stimulating the curiosity to learn" (p.45), in the belief that the instructor's effort to build an effective learning environment could be wasted, if the students' attention is distracted, or if the instructor is unable to gain the students' attention in the right way. Furthermore, Keller [28] highlights that people differ in their capacity to be stimulated by a learning situation; some individuals are easily bored, while others are more prone to feeling comfortable with a steady pace. According to Keller [30], the concept of attention is constructed from four other components: arousal theory, curiosity, boredom, and sensation-seeking.

\subsection{The Technology Acceptance Model (TAM)}

TAM was introduced by Davis [14] to examine the relationship between users' acceptance of an accounting information system, its PU, and its PEU. TAM was developed based on the Theory of Reasoned Action [54]. According to this theory, attitudes and norms influence the intention to perform a certain behaviour in future [1, 54]. An extension of this theory is the Theory of Planned Behaviour, which assumes that an individual's intention to engage in certain behaviour is determined by the perceived behavioural control [1].

TAM is considered to be the most influential model for examining users' acceptance or rejection of a technology innovation [32]. Davis [14] stresses the importance of 
examining learners' perceptions of technology based on PEU and PU, in order to avoid future failure in implementation. PU refers to "the degree to which an individual believes that using a particular system would enhance his or her job performance", while PEU refers to "the degree to which a person believes that using a particular system would be free of effort" [15, p.320]. In TAM, which is introduced by Davis et al. [16] (see Figure 1 , below), the acceptance of a technology is determined by the individual's ITU, which is in turn shaped by the user's ATU. The construct derived from this is determined by the users' own perceptions of the technology's usefulness (PU) and ease of use (PEU) [26]. Additionally, in TAM, PU is determined by PEU, but PU and PEU can also be affected by external variables such as features of technology and users' characteristics [23].

Nevertheless, inconsistent results have been reported in the literature, concerning the importance of PEU and PU in technology acceptance [43]. Davis [15] reported a strong effect of PEU on ITU, while Venkatesh [53] found that PU and PEU had a direct effect on ITU, predicting $35 \%$ of the variance on this basis. However, this effect appears to become weaker with time. In contrast, PU is a significant indicator, predicting students' ITU for AR technology in future [10]. Conversely, Rese et al. [43] claimed that PEU is not a predictor of ITU for technology, but $\mathrm{Hu}$ et al. [25] found PU to be a significant determinant of ITU, unlike PEU. These variations in the results for the relationship between PU, PEU and ITU for technology may relate to the effect of other external variables [43].

Following the above studies, the majority of researchers have extended TAM by adding other external variables, linking the two main variables (PEU and PU), to examine technology (AR) acceptance [32]. For example, Wixom and Todd [56] added those aspects of the system and information quality that influenced the PU of AR. Other studies have found that 'perceived enjoyment' to have a positive influence on users' attitudes to technology use [13, 52, 58]. Leue et al. [32] identified four potential variables that influence PEU and PU; and thus, users' attitudes towards and intention to use AR. These consisted of perceived benefits, enjoyment, personal innovativeness, cost, and information quality. More specifically, Chang et al. [10] found that system quality was an important factor in PU, perceived satisfaction, and AR-learning effectiveness. The above study also found that perceived self-efficacy affected perceived satisfaction and PU. Moreover, the learners' behavioral intention was affected by PU and perceived satisfaction with the AR-learning process.

Nevertheless, the original TAM concentrated more on extrinsic motivation, considering $\mathrm{PU}$ as an extrinsic motivating factor, with a need for more attention to intrinsic factors [53, 57]. Sánchez and Hueros [44] had previously examined this relationship between TAM and motivation; in their study, they dealt with the PU factor as an extrinsic motivating factor, with a focus on self-efficacy as an intrinsic factor of TAM. From the literature, they discovered that previous researchers had concentrated on TAM, but only its extrinsic factors. However, more recently, there has been a stronger trend towards exploring intrinsic factors. Moreover, Ibáñiez et al. [26] investigated the same aspect, highlighting perceived enjoyment and PU. These are considered as constructs of intrinsic and extrinsic motivation, respectively. By doing so, the above authors discovered that the factors had a positive impact on students' future ITU for AR.

Nevertheless, TAM has been criticized in the literature for being a self-reported scale, which lacks accurate measures [46]. Results of TAM should likewise be treated with caution, as conflicting findings are represented in the literature [20]. In fact, TAM is limited to explaining behavioral intention; it measures behavioral intention to use technology in future rather than its actual use [60]. Furthermore, TAM has been criticized for its omission of intrinsic factors that could influence technology acceptance [13, 39]. Therefore, the present study adds ATT as a new construct to the model, which aims to play a role in integrating an intrinsic factor into TAM.

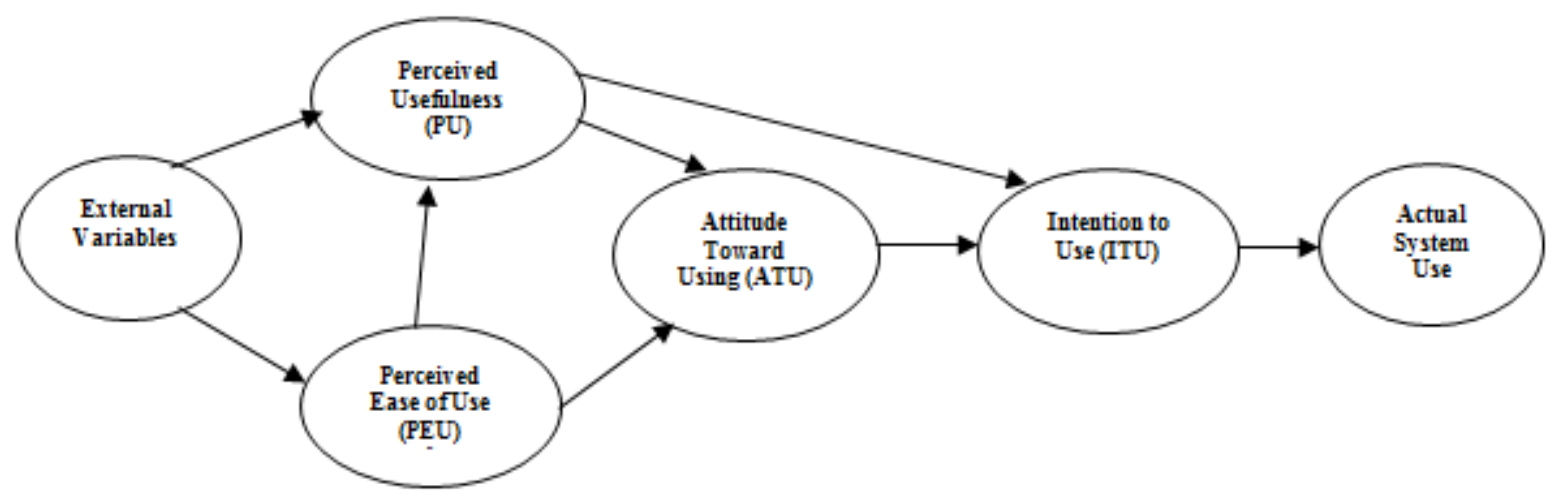

Figure 1. The technology acceptance model (Davis et al., 1989) 


\subsection{Previous Studies on the Technology Acceptance Model (TAM)}

To understand how the perception of a technology can influence task performance, a study by Liou et al. [34] was reviewed in this current research, wherein 54 students were divided into two groups in a quasi-experimental design. One group took an astronomy course using 2D image-based virtual reality (VR), while the other used AR for the same course. Pre- and post-test scores were then collected to compare the students' performance in the two groups. Finally, TAM was applied to investigate the learners' perceptions of these two technologies, with four constructs of TAM being used: PEU, PU, ATU and ITU.

The results of the above tests showed that the students who used AR on their course performed better in the post-test. This may relate to perceptions of the two technologies, which were more positive in the case of AR. However, this present study proved that there was no significant difference between PEU and ITU, but there were significant differences indicated for the PU and ATU constructs. The rationale for the significant differences found for the PU construct is that the AR group agreed that it could help them understand the sequence of phases of the moon and easily identify the direction of movement of the moon. Indeed, the students' attitudes to VR and AR differed, as the first group demonstrated lower quality interaction; AR provided the learners with a vivid learning experience, while VR did not offer the intellectual resources to help build the participants' knowledge. As such, it is concluded here that AR can increase students' perceptions of immediacy with regard to course content and their enjoyment of it, thereby promoting concentration It could also enable learners to integrate multimedia elements with a positive attitude, consequently reducing mental load.

Students' perceptions of AR using TAM have been widely investigated in the literature. For instance, Ibáñiez et al. [26] conducted a study to examine undergraduate engineering students' perceptions of AR, when used in learning activities based on TAM. The above researchers found that perceived enjoyment and attitudes to the activity had a positive impact on ITU for AR. Moreover, the intention to use systems is evaluated according to perceived enjoyment, rather than PU. Hence, it was found that PEU had a more positive impact than PU on perceived enjoyment, indicating that $\mathrm{AR}$ can motivate students to undertake tasks related to electromagnetism. Moreover, Wang et al. [54] sought to identify students' perceptions of $\mathrm{AR}$ maintenance instructions, as they claimed that the reported benefits of these instructions and the successful implementation of AR depended on users' acceptance of AR. For this reason, TAM was applied to explain and predict the relationships between PEU, PU, ATU and the ITU in following AR maintenance instructions. Forty-one students participated in the above study, receiving paper-based instructions on maintenance.
PEU and PU had a positive effect on the learners' attitudes to these AR instructions. Moreover, the learners' ITU for AR was affected by the PU but not by PEU. This indicates the importance of ease of use and usefulness, which should be developed to enhance students' attitudes, and consequently, their ITU for AR. These findings confirm the importance of the four TAM constructs for gaining a clear understanding of participants' perceptions of a technology.

Álvarez-Marín et al. [4] designed an AR app to support engineering students, as they worked with electrical circuits and developed an understanding of the functions of electricity. The above-mentioned authors used TAM to investigate students' perceptions of using AR technologies, the impact on their study, and their ITU for AR in future. A sample of 190 students participated by completing a self-reported questionnaire. The results revealed a positive effect of ITU and technology innovation on PU and ATU. This indicates that ATU is influenced by PU but not directly by PEU, signifying that students are willing to use this app not just because it is easy to use but it is also useful. The results showed that ATU explains behavioral ITU. Similar results were obtained by Gurer [23], who investigated the ITU for AR in a sample of 50 pre-service teachers in Turkey, in relation to the participants future careers. Moreover, Gurer found that the PEU and PU of AR affected the pre-service teachers' ATT. Possible justification for these results was subsequently provided, including the pre-service teachers' need for training, the existing technical infrastructure, and technical design and support in schools.

To assess TAM's effectiveness in examining e-learning acceptance and gaining a deeper understanding of the relationship between TAM constructs, Masrom [38] carried out research on 122 students at the College of Science and Technology in Malaysia, using the original version of TAM to investigate work-related tasks within TAM for e-learning. The above study findings reveal that the ITU of a technology is determined largely by its PU, rather than by the attitudes towards it. Furthermore, PEU was found to have a significant influence on both PU and ATU. In turn, PU appeared to have a significant influence on ATU. This is aligned with Davis [15], who found that attitudes to technology constituted a limited mediator of the effect of PU on ITU.

Meanwhile, Guerrero et al. [22] used AR in a Human Anatomy course and it is found that there is development in the students' interest, motivation, perception and learning, with less time required to review the subject. The above authors concluded from their literature review that AR motivates learning and enables content to be grasped more easily, because it shapes explanation and assimilation, and improves interaction between teachers and students. Moreover, AR can enhance students' attention, concentration, active participation, and positivity about learning. 
From the review of the literature presented here, it is clear that the effects of AR on learners' motivation, examined in light of TAM and IMMS, have been given extensive and consistent attention in the literature. Previous studies have found that there is a significant impact of AR on learners' achievement, intention and attention. However, there remains a need to explore how learners perceive the usefulness (PU) of AR and its PEU, looking at whether this correlates with their ATT and ITU for AR in future. Thus, from the existing literature, it is clear that the intrinsic aspect of TAM needs to be investigated in depth. As a result, this current study explores ATT as a construct of intrinsic motivation that could be added to TAM.

\section{Methodology}

\subsection{The Research Design}

A descriptive research design was applied in this current study, where quantitative methods were predominantly used to research specific topics. More precisely, a non-experimental correlational design was adopted, which was primarily concerned with studying the relationships within a group of variables. By using this design, the existence of a correlation between independent variables (PU, PEU) and a dependent variable (ATT) was studied. Moreover, it was ascertained whether there was a correlation between the independent variable (ATT) and dependent variable (ITU). Finally, an attempt was made to establish whether there was any correlation between the independent variables (PU, PEU) and dependent variable (ITU). A multiple linear regression method was applied to answer the research questions. This method helped identify the role played by the independent variables in explaining variance in the dependent variable.

\subsection{Sampling Procedure}

The sample in this study was selected in accordance with the authors' working environment, which is characterized by the typical gender segregation to be found in Saudi universities. A purposeful sampling approach was adopted, drawn from the population of female students registered on the Instructional Technology course, this being a mandatory course at the College. Although this sample is not representative of a wider population and the results cannot be generalized, the findings could still be helpful for researchers, in that they will be made aware of the participants' characteristics [47].

\subsection{Participants}

The participants in this current study were all female sophomores, majoring in kindergarten and elementary pre-teacher education, with Instructional Technology as one of their required courses at the College. Their ages ranged from 19 to 21 years, and they had a basic level of proficiency in technology use. Moreover, since all the students had completed the College's Computer Applications in Education course, they were aware of how to access and navigate the Internet. They were also capable of downloading apps as part of their daily activities, or to satisfy the requirements of their courses.

\subsection{Instrumentation}

The aim of this study was to evaluate the effect of AR on learners' ATT, looking at how this could affect their ITU for AR in future, as well as evaluating the effect of PEU and PU as predictors of ATT. To achieve this, a questionnaire was adapted from the TAM survey $[15,57]$ and IMMS questionnaire [30], modified by Di Serio et al. [18], after adopting the term, 'augmented reality'. The current study scale was translated into Arabic. This research instrument consisted of four constructs: PEU, PU, ITU (from TAM), and ATT (from IMMS), as presented in Figure 2. It consisted of a five-point Likert Scale, ranging from ' 5 ' ('Strongly agree') to ' 1 ' ('Strongly disagree'). There were also five reversed items.

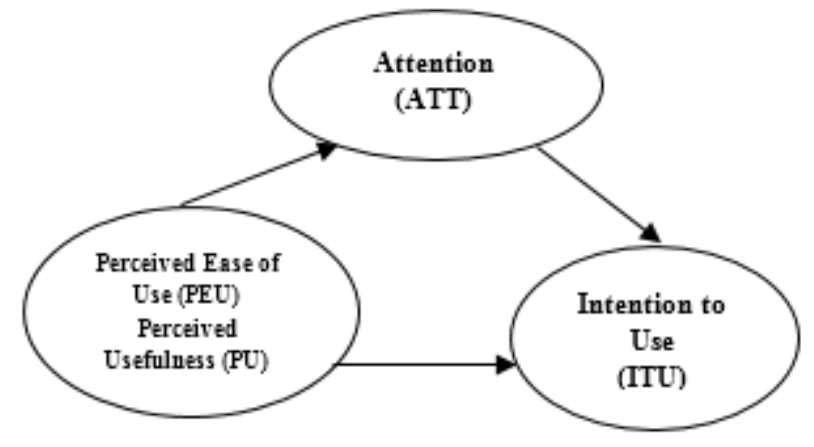

Figure 2. Research model used in this study

\subsection{Research Questions}

Research question 1: Do perceived ease of use (PEU) and perceived usefulness (PU) predict students' perceptions of augmented reality (AR) technology gaining their attention (ATT)?

Research question 2: Does the students' perceived attention (ATT) predict their intention to use (ITU) AR technology in future?

Research question 3: Do perceived ease of use (PEU) and perceived usefulness (PU) predict students' ITU for AR technology in future?

\subsection{Data Collection Procedure}

The data were collected from a sample of 101 students on an Instructional Technology course. These students 
were enrolled in five classes. The course was taught by two different instructors, but the instructions and content regarding the use of AR were the same. After every lecture and throughout the seven weeks of the semester, the students were introduced to videos, websites, and supplementary materials via AR. This content was used to enrich lectures and support the course with extra information, thereby helping the students better understand its content. After a short introduction on how to use AR, the students were able to scan cards so that $\mathrm{AR}$ content appeared. The app selected to create the AR was Zappar; it depended on creating code that the instructors could integrate into any material used in class. It also enabled the learners to interact with AR information about content when they clicked on a smartphone screen. The learners were asked to bring their smartphones with them to class, download the app, and use it. After the pre-teachers had engaged in this activity, a survey was distributed via email to all the participating students, to which they responded anonymously.

\section{Results}

\subsection{Descriptive Statistics}

The descriptive statistics derived from the statement scales are presented in Table 1, after calculating the mean and standard deviation. All mean values ranged from 3.10 to 4.55 , while the standard deviation ranged from 1.20 to .575 . In this study, the mean scores for the instrument items were classified into three levels as follows: low (1-2.3), moderate (2.4-3.6), and high (3.7-5.0). The mean scores for all items were high, but the mean scores for items 15, 16, 19 and 23 were moderate.

Table 1. Descriptive Statistics

\begin{tabular}{|c|c|c|c|}
\hline Items & Mean & Std. Deviation & Level \\
\hline 1. I found AR easy to use. & 4.45 & .608 & High \\
\hline 2. I thought learning to use AR would be easy for me. & 4.47 & .657 & High \\
\hline 3. I thought it would be easy for me to find information using AR. & 4.33 & .801 & High \\
\hline 4. I thought AR would enhance my effectiveness in learning. & 4.55 & .700 & High \\
\hline 5. I thought AR would improve my course performance. & 4.21 & .828 & High \\
\hline 6. I thought AR would increase my productivity in my coursework. & 4.16 & .809 & High \\
\hline 7. I found AR useful. & 4.54 & .575 & High \\
\hline 8. I would like to use the system in future, if I had the opportunity. & 4.42 & .752 & High \\
\hline 9. Using such a system would allow me to perform chemical experiments on my own. & 3.94 & 1.094 & High \\
\hline 10. I would like to use the system to learn chemistry and other subjects. & 4.38 & .773 & High \\
\hline 11. AR technology is attention-grabbing. & 4.44 & .684 & High \\
\hline 12. The quality of the AR material helped to hold my attention. & 4.30 & .843 & High \\
\hline 13. The material was so abstract that it was hard to keep my attention on it (Reversed). & 3.32 & 1.104 & Moderate \\
\hline $\begin{array}{l}\text { 14. The images, videos and text that I discovered through the lesson were unappealing } \\
\text { (Reversed). }\end{array}$ & 3.59 & 1.201 & Moderate \\
\hline $\begin{array}{l}\text { 15. The way that the information was arranged using this technology helped keep my } \\
\text { attention. }\end{array}$ & 4.06 & .835 & High \\
\hline 16. The information discovered through the experience stimulated my curiosity. & 3.99 & .831 & High \\
\hline 17. The amount of repetition of the activities bored me (Reversed). & 3.10 & 1.187 & Moderate \\
\hline 18. I learned some things though AR that were surprising or unexpected. & 3.93 & .816 & High \\
\hline 19. The variety of audio-visual material helped keep my attention on the lesson. & 4.30 & .715 & High \\
\hline 20. The audio-visual material was boring (Reversed). & 3.79 & .920 & High \\
\hline 21. There was so much content that it was irritating (Reversed). & 3.31 & 1.147 & Moderate \\
\hline
\end{tabular}




\subsection{Measures}

The validity and reliability of the original instruments had already been reported in the literature, both for TAM $[2,45]$ and IMMS $[6,7,18]$. However, as the model used in this research is a mix of these two previous models, the validity and reliability were constructed. The model implemented was consequently translated into Arabic and back into English by an independent researcher.

Content validity was assessed to verify that the statements in the instrument were well constructed and relevant to its constructs. This was performed by six experts, as suggested by Shrotryia and Dhanda [49]. These experts were asked to rate the statements using a four-point relevance scale, based on how well the items corresponded to their constructs, as follows: $(1)=\mathrm{Not}$ relevant; (2) = Somewhat relevant; $(3)=$ Quite relevant, and $(4)=$ Highly relevant . The Content Validity Index for each item (I-CVI) was calculated after the experts had given a rating of 1 or 2 a score equal to 0 , and a rating of 3 or 4 a score equal to 1 . According to Lynn [35], when six experts are engaged to assess content validity, items with a CVI of less than .83 should be eliminated. In the present case, however, all I-CVIs equal 1 , and two items $(13,17)$ had CVIs that equal .83 , which was within the acceptable range, based on Lynn[35], and Shi and Sun[48]. Two items had I-CVIs lower than .83, and a decision was made to delete them from the instrument, since they were vague and did not seem to be relevant to the constructs. This reduced the number of items in the instrument from 23 to 21 , and the remaining items were revised based on the experts' suggestions. The scale-level content validity index score, based on the average, was calculated for the scale $(\mathrm{S}-\mathrm{CVI} / \mathrm{Ave}=.93)$. According to Shi and Sun [48], a scale with an S-CVI/Ave of 0.9 or above should have excellent content validity.

In addition, the reliability of the scale constructs was tested. As may be seen in Table 2, the Cronbach's alpha values ranged from 0.5 to 0.7 , indicating homogeneity in the items, since they measured the same construct. However, the Cronbach's alpha for the whole scale was 0.857 . This value showed that the scale as a whole had good internal consistency based on George and Mallery [21], who suggest that a scale with a Cronbach's alpha equals .8 should have good internal consistency.

Table 2. Reliability of the instrument

\begin{tabular}{|c|c|c|c|}
\hline Construct & Item & $\begin{array}{c}\text { Cronbach's } \\
\text { Alpha }\end{array}$ & $\begin{array}{c}\text { Number of } \\
\text { Items }\end{array}$ \\
\hline PEU & $1,2,3$ & .662 & 3 \\
\hline PU & $4,5,6,7$ & .772 & 4 \\
\hline ITU & $8,9,10$ & .573 & 3 \\
\hline ATT & $\begin{array}{c}11,12,13,14,15,16,17, \\
18,19,20,21\end{array}$ & .761 & 11 \\
\hline
\end{tabular}

\subsection{Results and Analysis}

To understand the relationship between variables, the Pearson's correlation coefficient between them was calculated, using the Statistical Package for Social Sciences (SPSS) 19.0. Examining the Pearson's correlation between PU, PEU, ITU, and ATT revealed that all these variables were positively correlated, and these correlations between them were statistically significant, as shown in Table 3. This demonstrates that the students who indicated high PEU also reported high perceived ATT. Furthermore, the students who had high perceived ATT while using AR in their learning also showed high ITU for AR in future, and so on.

Table 3. Correlations between constructs

\begin{tabular}{|c|c|c|c|c|}
\hline & PEU & PU & ITU & ATT \\
\hline PEU & & $.508^{* *}$ & $.467 * *$ & $.513^{* *}$ \\
\hline PU & $.508^{* *}$ & & $.632^{* *}$ & $.542^{* *}$ \\
\hline ITU & $.467 * *$ & $.632^{* *}$ & & $.501 * *$ \\
\hline ATT & $.513^{* *}$ & $.542^{* *}$ & $.501 * *$ & \\
\hline
\end{tabular}

**. Correlation is significant at the 0.05 level (2-tailed).

To answer the first research question, a multiple regression analysis was performed to assess whether PEU and PU were significant predictors of ATT. The purpose of using multiple regression in answering this question was to investigate the effect of PU and PEU on predicting ATT, since the literature highlighted that these variables are motivational [26, 44, 53, 57]. Thus, this question sought to ascertain whether the intrinsic motivational variable (ATT) can be predicted from the extrinsic motivational variables (PU and PEU). The regression model for predicting the students' ATT while using AR, based on PEU and PU, showed that $\mathrm{R}=0.564, \mathrm{R}^{2}=0.318$ and $\mathrm{SE}=4.73$. This indicates that the students' PEU and PU predicted $31.8 \%$ of the variance in their level of ATT while learning using AR technology. Indeed, the overall regression for this model was statistically significant: $\mathrm{F}(2,98)=22.89, \quad \mathrm{MS}=511.590, \quad \mathrm{p}<0.05$. The results indicated PEU as a significant predictor of ATT, when controlling for PU: $\mathrm{t}(98)=2.932, \mathrm{p}<0.05$. In addition, PU was found to be a significant predictor of ATT when controlling for PEU: $\mathrm{t}(98)=4.127, \mathrm{p}<0.05$, and both variables appeared to be significant predictors of ATT.

When examining and comparing the standardized coefficients of PEU and PU, it was clear that both predictors were almost equally responsible for the changes in ATT, with a beta value equaling 0.274 and 0.385 , respectively. The multiple regression equation for this model to predict ATT from PEU and PU is as follows:

$$
\mathrm{Y} 1=12.523+0.966 \mathrm{X} 1+.964 \mathrm{X} 2
$$

where $\mathrm{Y} 1$ is the score of ATT, X1 is the score of PEU, and $\mathrm{X} 2$ is the score of PU. 
When investigating the assumption of collinearity in all the models, the result indicated no concerns over multicollinearity (Tolerance and VIF for PEU and PU are as follows: Tolerance $=0.797$ and $\mathrm{VIF}=1.25$ ).

To answer the second research question, linear regression was performed to assess whether ATT was a significant predictor of ITU. Linear regression was applied in response to this question, exploring the possibility of adding the intrinsic motivational variable (ATT) to TAM by drawing a prediction relationship between it and ITU, given that Cheng [11] suggested a relationship between them. The regression model for predicting the students' ITU for AR from ATT showed that $\mathrm{R}=0.464$ and $\mathrm{R}^{2}=0.215$. That is, $A R$ 's capacity to gain the students' attention while learning could predict $21.5 \%$ of the variance in the students' ITU for AR in future. Indeed, the regression model for predicting ITU from ATT was statistically significant: $F(1,99)=27.179$, $\mathrm{MS}=82.24, \mathrm{p}<0.05$. The results revealed ATT to be a significant predictor of ITU: $\mathrm{t}(99)=5.213, \mathrm{p}<0.05$. The linear regression equation for this model to predict ITU from ATT is therefore as follows:

$$
\mathrm{Y} 1=5.989+0.160 \mathrm{X} 1
$$

where Y1 is the score of ITU, and X1 is the score of ATT.

To answer the third research question, a multiple regression analysis was performed to assess whether PEU and PU were significant predictors of ITU. It was decided to use regression of this type to investigate the effect of PU and PEU on ITU, because the literature revealed that both PU and PEU have an effect on ITU $[32,53]$. The regression model for predicting the students' ITU for AR in future, based on PEU and PU, showed that $\mathrm{R}=0.639$ and $\mathrm{R}^{2}=0.408$. This indicates that the students' PEU and PU predicted $40.8 \%$ of the variance in ITU. Thus, the overall regression for this model was statistically significant: $\mathrm{F}(2,98)=33.817, \mathrm{MS}=77.947, \mathrm{p}<0.05$. $\mathrm{PEU}$ is not a significant predictor of ITU when controlling for PU: $\mathrm{t}(98)=1.245, \mathrm{p}=0.216$. However, $\mathrm{PU}$ is a significant predictor of ITU when controlling for PEU: $\mathrm{t}(98)=6.698$, $\mathrm{p}<0.05$. It is worth mentioning that when PEU alone was entered into the regression model to predict ITU; PEU was a significant predictor of ITU: $\mathrm{t}(98)=3.972, \mathrm{p}<0.05$. The multiple regression equation that is used to predict ITU from PEU and PU is as follows:

$$
\mathrm{Y} 1=2.207+.132 \mathrm{X} 1+.503 \mathrm{X} 2
$$

where $\mathrm{Y} 1$ is the score of ITU, X1 is the score of PEU, and $\mathrm{X} 2$ is the score of PU.

\section{Discussion and Conclusions}

This current study revealed that the students who perceived a high level of ease of use (PEU) and perceived usefulness (PU), also reported a high level of perceived attention (ATT). In addition, it indicated that PU and PEU are significant predictors of ATT. In particular, this is partially supported by Cheng [11], who found a positive relationship between PU and ATT. It was clear that the pre-teachers in the present study found it easy to use AR technology, as confirmed by Martín-Gutiérrez et al. [36], because they were merely required to scan a barcode and then select the media that they wished to access. Moreover, they found AR useful for their learning, as confirmed by Álvarez-Marín et al. [4] and Liou et al. [34], since it helped them to expand on explanations of course content. Students would perceive technology as useful whenever it met their needs [42]. The PEU and PU of AR, in the form of videos, images, figures, and sample lessons, helped capture and retain the pre-teachers' attention while they were learning, and enhanced their understanding of the content. As Keller [28] suggests, being able to sustain learners' attention is a prerequisite for learning.

A second finding from this study was that the retention of pre-teachers' ATT while learning in the classroom was a significant predictor of their ITU for AR. Few studies have addressed this relationship. Álvarez-Marín et al. [4] and Gurer [23] found that ATU explains pre-service teachers' behavioral ITU for AR in future. However, Cheng [11] identified a relationship between students' ITU and ATT, which was observed to have the effect of mediating between PU and ITU. The use of AR demonstrated development in the learners' motivation, attention and perceptions $[18,22]$. This can take place if explanation and interactive opportunities are made available, whereby students are invited to discuss what they have encountered in the learning material provided via $A R$, and to answer questions put to them by their teacher. Furthermore, AR can be used to present learners with attractive learning content, which engages them more effectively than paper-based content [22]. It seems that gaining learners' attention using AR is related to their ITU for this technology in future, which can predict their intention, since the technology will motivate them to engage in further usage in future. Attention is an intrinsic motivational factor in this current study, but it represents an intrinsic variable that has received little research attention over the years. Thus, gaining learners' attention is one of the variables that could be added to TAM. It played a role in extending the current model to include more intrinsic variables.

This study also found that PU and PEU combined as a model predicted the students' future ITU. Here, PU was a significant predictor of ITU, but PEU was not. PU has been found to have a significant effect on the acceptance of AR and students' ITU at a later date, as confirmed by Álvarez-Marín et al. [4], Chang et al. [10], Ibáñiez et al. [26], and Masrom [38]. Furthermore, this finding is in line with $\mathrm{Hu}$ et al. [25], Rese et al. [43], and Wang et al. [54], who found that learners' ITU for AR was directly affected by PU, rather than PEU. Furthermore, Liou et al. [32], found that there are no significant differences between 
PEU and ITU. In contrast, Davis [15] reported that both PU and PEU were predictors of ITU that could change over time. Indeed, it appears that learners' PU of AR attracted their attention, which then increased the likelihood of them using it in future [11]. In sum, the pre-teachers found AR to be useful and they planned to use it in their future careers. They were technology-savvy and possessed skills for the digital age, meaning that it was of little direct importance to them whether the technology was easy to use, as a factor of their intention to continue using it in future. Instead, it was of high importance for them at this stage of their learning to be able to access technology that would be useful and beneficial to them in their learning.

\section{Limitations of the Study}

This current study throws up many questions in need of further investigation. For instance, the study participants were exclusively female, and this raises the question of whether male learners have the same perceptions of AR. In addition, the study did not test all constructs in TAM and other constructs, such as users' attitude towards using AR, AR's features and users' characteristics. Thus, it is recommended that further research should be conducted to investigate AR acceptance, using these constructs. Moreover, TAM can only evaluate and predict the capabilities of technology, without giving detailed diagnoses of the flaws in that technology [38].

\section{REFERENCES}

[1] Abduljalil K. M., Zainuddin Y., "Integrating technology acceptance model and motivational model towards intention to adopt accounting information system," International Journal of Management, Accounting and Economics, vol. 2, no. 1, pp. 346-359, 2015.http://citeseer x.ist.psu.edu/viewdoc/download?doi=10.1.1.734.9583\&rep $=$ rep $1 \&$ type $=$ pdf

[2] Agarwal R., Karahanna E., "Time flies when you're having fun: Cognitive absorption and beliefs about information technology usage," MIS Quarterly, vol. 24, no.4, pp. 665694, 2000. https://doi.org/10.2307/3250951

[3] Akçayır M., Akçayır G., "Advantages and challenges associated with augmented reality for education: A systematic review of the literature," Educational Research Review, vol. 20, pp. 1-11, 2017.https://doi.org/10.1016/j.e durev.2016.11.002

[4] Álvarez-Marín A., Velázquez-Iturbide J. Á., Castillo-Vergara M., "Technology Acceptance of an Interactive Augmented Reality App on Resistive Circuits for Engineering Students, " Electronics, vol. 10, no. 11, pp. 1-14, 2021. https://doi.org/10.3390/electronics10111286

[5] Azuma R.T., "A survey of augmented reality," Presence:
Teleoperators and Virtual Environments, vol. 6, no. 4, pp. 355-385, 1997. https://doi.org/10.1162/pres.1997.6.4.355

[6] Bacca J., Baldiris S., Fabregat R., Kinshuk, "Insights into the factors influencing student motivation in augmented reality learning experiences in vocational education and training," Frontiers in Psychology, vol. 9, pp. 1486, 2018. https://doi.org/10.3389/fpsyg.2018.01486

[7] Bolliger D. U., Supanakorn S., Boggs C., "Impact of podcasting on student motivation in the online learning environment," Computers \& Education, vol. 55, no. 2, pp. 714-722, 2010. https://doi.org/10.1016/j.compedu.2010.03 .004

[8] Bower M., Howe C., McCredie N., Robinson A., Grover D., "Augmented reality in education-cases, places and potentials," Educational Media International, vol. 51, no. 1, pp. 1-15, 2014. https://doi.org/10.1080/09523987.2014.88 9400

[9] Brom C., Šisler V., Slavík R., "Implementing digital game-based learning in schools: augmented learning environment of 'Europe 2045'," Multimedia Systems, vol. 16, no. 1, pp. 23-41, 2010.https://doi.org/10.1007/s00530009-0174-0

[10] Chang Y. J., Chen C. H., Huang W. T., Huang W. S., "Investigating students' perceived satisfaction, behavioral intention, and effectiveness of English learning using augmented reality," 2011 IEEE International Conference on Multimedia and Expo, Barcelona, Spain, Jul., 2011, pp.1-6. https://doi.org/10.1109/ICME.2011.6012177

[11] Cheng K., "Reading an augmented reality book: An exploration of learners' cognitive load, motivation, and attitude," Australasian Journal of Educational Technology, vol. 33, no. 4, pp. 53-69, 2017. https://doi.org/10.14742/aj et. 2820

[12] Chiang T. H., Yang S. J., Hwang G. J., "Students' online interactive patterns in augmented reality-based inquiry activities," Computers \& Education, vol. 78, pp. 97-108, 2014. https://doi.org/10.1016/j.compedu.2014.05.006

[13] Chung J., Tan F. B., "Antecedents of perceived playfulness: An exploratory study on user acceptance of general information-searching websites," Information and Management, vol. 41, no. 7, pp. 869-881, 2004. https://doi.org/10.1016/j.im.2003.08.016

[14] Davis F. D., "A technology acceptance model for empirically testing new end-user information systems: theory and results," (PhD thesis), Sloan School of Management, Massachusetts Institute of Technology, 1985.

[15] Davis F. D., "Perceived usefulness, perceived ease of use, and user acceptance of information technology," MIS Quarterly, 13(3), vol. 13, no. 3, pp. 319-340, 1989. https://doi.org/10.2307/249008

[16] Davis F. D., Bagozzi R. P., Warshaw P. R., "User acceptance of computer technology: A comparison of two theoretical models, " Management science, vol. 35, no. 8, pp. 982-1003, 1989. https://doi.org/10.1287/mnsc.35.8.982

[17] Dede C., "Immersive interfaces for engagement and learning," Science, vol. 323, no. 5910, pp. 66-69, 2009. https://doi.org/10.1126/science.1167311 
[18] Di Serio Á., Ibáñez M. B., Kloos C. D., "Impact of an augmented reality system on students' motivation for a visual art course," Computers \& Education, vol. 68, pp. 586-596, 2013. https://doi.org/10.1016/j.compedu.20 12.03 .002

[19] Dunleavy M., Dede C., Mitchell R., "Affordances and limitations of immersive participatory augmented reality simulations for teaching and learning," Journal of Science Education and Technology, vol. 18, no. 1, pp. 7-22, 2009. https://doi.org/10.1007/s10956-008-9119-1

[20] Gangwar H., Date H., Raoot A. D., "Review on IT adoption: insights from recent technolnoies " Inurnal of Fnternrise Information Management, vol. 27, no. 4, pp. 488-502, 2014. https://doi.org/10.1108/JEIM-08-2012-0047

[21] George D., Mallery P., "Using SPSS for Windows Step by Step: A Simple Guide and Reference," 4th ed., Pearson Education, 2003.

[22] Guerrero J. S., Mera J. S., López W. G., Reinoso R. S., Dávila C. T., "Use of Augmented Reality AR in University Environments," 2018 International Conference on eDemocracy \& eGovernment, Ambato, Ecuador, Apr., 2018, pp. 291-297. https://doi.org/10.1109/ICEDEG.2018. 8372323

[23] Gurer M. D., "Examining technology acceptance of pre-service mathematics teachers in Turkey: A structural equation modeling approach, " Education and Information Technologies, pp. 4709-4729, 2021. https://doi.org/10.100 7/s10639-021-10493-4

[24] Hrastinski S., "A theory of online learning as online participation," Computers \& Education, vol. 52, no. 1, pp. 78-82, 2009. https://doi.org/10.1016/j.compedu.2008.06.0 09

[25] Hu P. J., Chau P. Y., Sheng O. R., Tam K. Y., "Examining the technology acceptance model using physician acceptance of telemedicine technology," Journal of Management Information Systems, vol. 16, no. 2, pp. 91112, 1999. https://doi.org/10.1080/07421222.1999.115182 47

[26] Ibáñiez M.B., Di Scrio A., Villarán D., Delgado-Kloos C., "The Acceptance of Learning Augmented Reality Environments: A Case Study," 2016 IEEE 16th International Conference on Advanced Learning Technologies, Austin, TX, Jul., 2016, pp. 307-311. https://doi.org/10.1109/ICALT.2016.124

[27] Johnson L., Smith R., Levine A., Haywood K., "The 2010 Horizon Report: Australia-New Zealand Edition," Austin, TX, The New Media Consortium, 2010 https://files.eric.ed.gov/fulltext/ED513479.pdf

[28] Keller J. M., "Development and use of the ARCS model of instructional design," Journal of Instructional Development, vol. 10, no. 3, pp. 2-10, 1987a. https://doi.org/10.1007/BF02905780

[29] Keller J. M., "The systematic process of motivational design," Performance \& Instruction, vol. 26, no. 9 - 10, pp. 1-8, 1987b.http://terrikrause.com/Content/documents/Kell er1987Systematic.pdf

[30] Keller J. M., "Motivational Design for Learning and Performance: The ARCS Model Approach," 1st ed.,
Springer, 2010. pp. 1-323. https://doi.org/10.1007/978-1-4 419-1250-3

[31] Kerawalla L., Luckin R., Seljeflot S., Woolard A., "'Making it real": Exploring the potential of augmented reality for teaching primary school science," Virtual Reality, vol. 10, no. 3-4, pp. 163-174, 2006. https://doi.org/10.1007/s10055-006-0036-4

[32] Leue M., Jung T. H., "A theoretical model of augmented reality acceptance," E-review of Tourism Research, vol. 5, no. 1, pp. 1-5, 2014. https://www.researchgate.net/publicat ion/267762847_A_Theoretical_Model_of_Augmented_Re ality_Acceptance

[33] Li K., Keller J. M., "Use of the ARCS model in education: A literature review," Computers \& Education, vol. 122, pp. 54-62, 2018. https://doi.org/10.1016/j.compedu.2018.03.0 19

[34] Liou H. H., Yang S. J., Chen S. Y., Tarng W., "The influences of the 2D image-based augmented reality and virtual reality on student learning," Journal of Educational Technology \& Society, vol. 20, no. 3, pp. 110-121, 2017. https://www.jstor.org/stable/26196123

[35] Lynn M.R., "Determination and quantification of content validity," Nursing Research, vol. 35, no. 6, pp. 382-386, 1986. https://doi.org/10.1097/00006199-198611000-00017

[36] Martín-Gutiérrez J., Fabiani P., Benesova W., Meneses M. D., Mora C. E., "Augmented reality to promote collaborative and autonomous learning in higher education," Computers in Human Behavior, vol. 51, pp. 752-761, 2015. https://doi.org.10.1016/j.chb.2014.11.093

[37] Martins V. F., Gomes L., de Paiva Guimarães M., "Challenges and Possibilities of Use of Augmented Reality in Education," International Conference on Computational Science and Its Applications, Basel, June, 2015, pp. 223 233. https://doi.org/10.1007/978-3-319-21413-9_16

[38] Masrom M., "Technology acceptance model and e-learning. Technology, vol. 21, no. 24, p. 81, 2007.https://citeseerx.i st.psu.edu/viewdoc/download?doi=10.1.1.554.6982\&rep=r ep1\&type $=$ pdf

[39] Moon J., Kim Y., "Extending the TAM for a world-wide-web context," Information and Management, vol. 38, no. 4, pp. 217-230, 2001. https://doi.org/10.1016/ S0378-7206(00)00061-6

[40] Ozdamli F., Hursen C., "An emerging technology: Augmented reality to promote learning," International Journal of Emerging Technologies in Learning (iJET), vol. 12, no. 11, pp. 121-137, 2017. https://doi.org/10.3991/ijet. v12i11.7354

[41] Poushneh A., "Augmented reality in retail: A trade-off between user's control of access to personal information and augmentation quality," Journal of Retailing and Consumer Services, vol. 41, pp. 169-176, 2018. https://doi.org/10.10 16/j.jretconser.2017.12.010

[42] Rahmat M. K., Nizar N. N. M., "Modelling the Successful Integration of Mobile Augmented Reality Technology (MART) Among Malaysian Pre-Service Teachers, " International Journal of Education, Psychology and Counseling, vol. 6, no. 38, pp. 57-65, 2021. https://doi.org/10.35631/IJEPC.638006 
[43] Rese A., Baier D., Geyer-Schulz A., Schreiber S., "How augmented reality apps are accepted by consumers: A comparative analysis using scales and opinions," Technological Forecasting and Social Change, vol. 124, pp. 306-319, 2017. https://doi.org/10.1016/j.techfore.2016.10. 010

[44] Sánchez R. a., Hueros A. D., "Motivational factors that influence the acceptance of Moodle using TAM," Computers in Human Behavior, vol. 26, no. 6, pp. 16321640, 2010. https://doi.org/10.1016/j.chb.2010.06.011

[45] Sánchez-Franco M. J., Roldán J. L., "Web acceptance and usage model: A comparison between goal-directed and experiential web users," Internet Research, vol. 15, no. 1, pp. 21-48, 2005. https://doi.org/10.1108/1066224051057 7059

[46] Segars A. H., Grover V., "Re-examining perceived ease of use and usefulness: A confirmatory factor analysis," MIS Quarterly, vol. 17, no. 4, pp. 517-525, 1993. http://doi:10.2307/249590

[47] Sharma G., "Pros and cons of different sampling techniques," International journal of applied research, vol. 3, no. 7, pp. 749-752, 2017.

[48] Shi J., Mo X., Sun Z., "Content validity index in scale development," Zhong Nan Da Xue Xue Bao Yi Xue Ban, vol. 37, no. 2, pp. 152-155, 2012. https://doi.org/10.3969/j. issn.1672-7347.2012.02.007

[49] Shrotryia V. K., Dhanda U., "Content validity of assessment instrument for employee engagement," Sage Open, vol. 9, no. 1, pp. 1-7, 2019. https://doi.org/10.1177/21582440188 21751

[50] Sural I., "Augmented reality experience: Initial perceptions of higher education students," International Journal of Instruction, vol. 11, no. 4, pp. 565-576, 2018. https://doi.or g/10.12973/iji.2018.11435a

[51] Sutherland I. E., "A head-mounted three-dimensional display," Fall Joint Computer Conference, Washington D.C., USA, Dec., 1968, pp. 757-764. https://doi.org/10.11 45/1476589.1476686

[52] Teo T., Noyes J., "An assessment of the influence of perceived enjoyment and attitude on the intention to use technology among pre-service teachers: A structural equation modeling approach," Computers \& Education, vol. 57, no. 2, pp. 1645-1653, 2011. https://doi.org/10.1016/j.c ompedu.2011.03.002

[53] Venkatesh V., "Determinants of perceived ease of use: Integrating control, intrinsic motivation, and emotion into the technology acceptance model," Information Systems Research, vol. 11, no. 4, pp. 342-365, 2000 https://doi.org/10.1287/isre.11.4.342.11872

[54] Wang Y., Anne A., Ropp T., "Applying the Technology Acceptance Model to understand aviation students' perceptions toward augmented reality maintenance training instruction," International Journal of Aviation, Aeronautics, and Aerospace, vol. 3, no. 4, pp. 1-13, 2016. https://doi.org/10.15394/ijaaa.2016.1144

[55] Wang C. H., Chi P. H., "Applying Augmented Reality in Teaching Fundamental Earth Science in Junior High Schools, " Computer Applications for Database, Education, and Ubiquitous Computing, Berlin, Heidelberg, 2012, pp. 23-30. https://doi.org/10.1007/978-3-642-35603-2_4

[56] Wixom B. H., Todd P. A., "A theoretical integration of user satisfaction and technology acceptance," Information Systems Research, vol. 16, no. 1, pp. 85-102, 2005. https://doi.org/10.1287/isre.1050.0042

[57] Wojciechowski R., Cellary W., "Evaluation of learners' attitude toward learning in ARIES augmented reality environments," Computers \& Education, vol. 68, pp. 570-585, 2013. https://doi.org/10. 1016/j.compedu.2013.02.014

[58] Wu J. H., Chen Y. C., Lin L. M., "Empirical evaluation of the revised end user computing acceptance model," Computers in Human Behavior, vol. 23, no. 1, pp. 162-174, 2007. http://doi.org/10.1016/j.chb.2004.04.003

[59] $\mathrm{Wu}$ T., "Improving the effectiveness of English vocabulary review by integrating ARCS with mobile game - based learning," Journal of Computer Assisted Learning, vol. 34, no. 3, pp. 315-323, 2018. http://doi.org/10.1111/jcal.12244

[60] Wu W. W., "Developing an explorative model for SaaS adoption," Expert systems with applications, vol. 38, no. 12, pp. 15057-15064, 2011.https://doi.org/10.1016/j.eswa.201 1.05.039 